include the development of appropriate accredited qualifications for providers of non-surgical interventions and it should determine accreditation requirements for the various professional groups. This work should be completed in 2013.

- Surgical providers should provide both the person undergoing a procedure and their GP with proper records.

- A breast implant registry should be established within the next 12 months and extended to other cosmetic devices as soon as possible, to provide better monitoring of patient outcomes and device safety.

With respect to an informed and empowered public, the following recommendations were made:

- The RCS Interspecialty Committee on Cosmetic Surgery should develop and describe a multi-stage consent process for operations. Consent must be taken by the surgeon performing the operation to ensure that the patient and practitioner have a shared understanding of the desired outcome and the limitations, implications, and risks of the procedure.

- Evidence-based standardised patient information should be developed by the RCS Interspecialty Committee on Cosmetic Surgery, with input from patient organisations.

- For non-surgical procedures, a record of consent must be held by the provider.

- Existing advertising recommendations and restrictions should be updated and better enforced.

- The use of financial inducements and time-limited deals to promote cosmetic interventions should be prohibited to avoid inappropriate influencing of vulnerable consumers.
With regards to accessible resolution and redress, the following recommendations were made:

- The remit of the Parliamentary and Health Service Ombudsman (PHSO) should be extended to cover the whole private healthcare sector. This will de facto include cosmetic procedures of all kinds.

- All individuals performing cosmetic procedures must possess adequate professional indemnity cover that is commensurate with the type of operations being performed.

- The Review Committee supports the future development of insurance products, such as risk pool arrangements, to cover product failure and certain complications of surgery.

The Royal College of Surgeons of England's Professional Standards for Cosmetic Practice provides guidance to clinicians for ethical practice. The Department of Health's Review of the Regulation of Cosmetic Interventions provides guidance to the government and forms a framework for new legislation. Neither is legally binding, but Hair Transplant Surgeons in the UK need to be aware that principles laid out in these two documents might become part of government legislation in the future. The European Union's European Standard for Aesthetic Surgery Services is undergoing final draft review and is also likely to have an impact on Hair Transplant Surgery provision in the UK when it is published

\section{References}

1. http://www.rcseng.ac.uk/publications/docs/professionalstandards-for-cosmetic-practice/

2. http://www.ncepod.org.uk/2010report2/downloads/CS_ report.pdf

\title{
European regulations
}

\section{Jean Devroye, MD Brussels, Belgium officedevroye@aol.com}

In May 2011, a European project was implemented by Belgian and European aesthetic surgeons. This project was intended to define exactly the rules applicable to medicine and to plastic surgery. The text represented a great danger at that time because there was an obvious will to reserve the practice of medicine and plastic surgery-including hair transplant surgery-exclusively to aesthetic and plastic surgeons. Over the past few months, following the strong reactions from dermatologists, associations of aesthetic doctors, and of the ISHRS (through my representation), the list restricting the attribution of every type of surgery or medicine to a particular type of doctor was removed from the project.

As far as skills are concerned, the present text reads: "The practitioner shall be a medical doctor authorized by national competent authority to practice autonomously. Assistants shall be medical doctors (in training) or nurses who shall be working under the doctor's supervision."

The skills would thus be decided by each European state according to its own legislation.

The European Committee for Standardization(CEN) project is on its way. The other main chapters in this document are Management and Communication with Patients, the Facilities (safety and security, hygiene standards, documentation of medical records), and Procedures (anesthesia, specific requirements and recommendations for aesthetic surgery services).

If you wish to receive the last version of the CEN project, email me at officedevroye@aol.com.
On the other hand, in Belgium, the situation was strongly clarified over these past two years. A new law governing the aesthetic activities of surgery and medicine was introduced in March 2013.

Thanks to the Belgian Society of Aesthetic Medicine (SBME) and its president, Jean Hebrant, the creation of a new specialization was decided (specialist in non-surgical aesthetic medicine). The practitioner trained for 5 years after his basic medical degree will have the possibility of practicing all aspects of aesthetic medicine as well as hair transplantation. I personally worked a lot so that the follicular hair transplant is considered as a non-surgical act, and the law stipulates it expressly. ${ }^{1}$

Also, the doctors who have practiced hair transplantation for at least 5 years can continue their practice.

As a conclusion, I think that the future promises us a hardening of the laws and the access for the practice of the hair transplantation in Europe. It is, however, interesting to fight to obtain the right for every doctor to exercise such specific practice. The results obtained with the CEN and with the Belgian government prove that our action of defense was effective.

\section{Reference}

1. http://www.dominiquetilmans.be/download/ Projet $\% 20 \mathrm{de} \% 201$ ioi $\% 205-62 \% 20$ complet\%20et\%20amen de\%20par\%20la\%20Chambre.pdf 